1870 he acted twice as private assistant to Sir James Paget, several of whose works he afterwards edited. From 1873 until 1891, when he became full surgeon, he served as assistant surgeon to St. Bartholomew's Hospital, where he lectured on anatomy, practical surgery and orthopædics. In 1903 he was appointed professor of surgery at Cambridge in succession to Sir George Murray Humphry, who had died in 1896, and in 1907 succeeded Dr. Alexander Hill as master of Downing College. He was the author of "Diseases of the Joints" (1886), which went through three editions and was translated into German, "Clinical Lectures and Essays" (1902) and numerous contributions to St. Bartholomew's Hospital Reports. Besides the distinctions already mentioned, Marsh was an honorary fellow of the Royal Academy of Medicine in Ireland, president of the Clinical Society of London and a corresponding member of the Orthopædic Society of New York. He died on June 24, 1915. A sympathetic obituary notice by Sir D'Arcy Power, accompanied by his portrait, appeared in St. Bartholomew's Hospital Reports $(51,1 ; 1915)$.

\section{The Bastardy (Blood Tests) Bill}

IT is to be hoped that the Bastardy (Blood Tests) Bill, which was given its second reading after a debate in the House of Lords on February 8 (Nature, Feb. 18, 294), will duly pass into law. The use of blood group tests has already become a common practice in several other countries, notably Sweden, Germany and the United States. The Bill provides that the Lord Chancellor may make rules under the Act, governing the taking, identifying and posting of blood samples, the form of certificate to be given, the qualifications of the 'approved persons' who make the tests, and the scale of fees payable. It may be pointed out that the $M$ and $N$ tests require much more skill in determination than the $A$ and $B$. It would therefore seem desirable for a local practitioner to take the samples as arranged and send them to one of a very limited number of experts who would make the actual tests. The Galton Laboratory is one of the very few places where the $M$ and $N$ as well as the $A$ and $B$ tests are constantly being made as a routine operation. In Denmark, a Government laboratory has been established for the purpose, where the tests are made for a small charge. Probably a similar arrangement would be best for Great Britain.

\section{Television in Cinemas}

THE practical application of television moved a step forward on February 23, when a view of the whole progress of the British light-weight boxing championship was transmitted from the Harringay arena. On this occasion, for the first time, the television programme was relayed to three cinema theatres in the West End of London, where the public had paid for admission. A report in The Times states that two of these theatres used Baird apparatus, while the third used the Scophony system. These cinemas became in effect overflow meeting places, where those unable to watch the fight in the arena could still follow its progress in black and white pictures; and the view so provided on a fifteen foot screen was the equivalent of a ring-side seat. Ait the transmitting end, two cameras were used, one giving a general view of the ring with the spectators scarcely visible in the surrounding darkness, while the other gave a close-up view of the two boxers. The latter was used most of the time and enabled viewers to watch the detailed progress of the contest. With the exception of one or two occasions, when there appeared to be a loss of synchronism in the transmitted pictures, the apparatus worked quite satisfactorily, and the accompanying running commentary was up to the usual high standard for sound broadcasting. The successful transmission of this fight demonstrated that such an event is very suited to television, and that the inevitable technical difficulties of relaying the programme to cinemas have been largely overcome. As a result, according to a further announcement in The Times, Baird television apparatus is to be installed in some 350 cinemas controlled by the Gaumont-British Picture Corporation.

\section{University of Birmingham: Annual Report}

IN the report of the Council which was presented to the Court of Governors at its annual meeting on February 23, reference is made to two recent benefactions, namely, one of $£ 10,000$ by Sir Charles Hyde and the other of $£ 2,000$ by the Pro-Chancellor and Mrs. Barrow. These were given as peace thankofferings. Sir Charles Hyde's gift, to be applied to a purpose chosen by the Prime Minister, is to be known as the Neville Chamberlain Physical Fitness Fund, and the income is to be used towards the maintenance of the University's scheme for physical education. The contribution of Mr. and Mrs. Barrow is to be added to the Medical School building fund. Mrs. Ellen M. Parrott has given $£ 500$ in memory of her late husband, to be known as the T. H. Parrott Geological Research Fund, for "advancement of research in Geology". Dr. and Mrs. Edward Cadbury, who recently provided funds for the building of the St. Francis Hall, have given a further sum of $£ 3,000$, the income of which is to be used for the maintenance of the Hall. As part of the scheme for physical education, a gymnasium (with ancillary rooms and three squash courts and one fives court) is to be built at a cost of $£ 15,000$, of which $£ 10,000$ has been promised by the University Grants Committee and $£ 5,000$ by a private benefactor. Funds for the establishment of a department for research into mental diseases in the new building of the Medical School have been guaranteed for a number of years. The laboratories are now occupied, and Dr. Stanley Barnes has been appointed honorary director of mental diseases research, with Dr. F. A. Pickworth as senior research officer. Several investigations into cancer, financed by the Local Committes of the British Empire Cancer Campaign, are being carried out in the new Medical School. The Poynting Memorial Lecture is to be given on March 7 in the Physics Department by Dr. H. B. G. Casimir, of Leyden, on "The Approach to the Absolute Zero of Temperature, and the Properties of Matter at the 